\title{
Inversion Precipitable Water Vapor by GPS Observation of CMONOC
}

\author{
Hongbo Shi ${ }^{1}$, Rui Zhang ${ }^{1}$, Zhaosheng $\mathrm{Nie}^{2}$, $\mathrm{Yu} \mathrm{Li}^{1}$, Zhengsong Chen ${ }^{2}$ and Tan Wang ${ }^{1}$ \\ 1. National Earthquake Infrastructure Service, Beijing 100045, China \\ 2. Institute of earthquake administration, China Earthquake Administration, Hubei 430071, China
}

\begin{abstract}
In this study, we have processed the GPS (Global Position System) and meteorological data from about 220 stations of CMONOC (Crustal Movement Observation Network of China in short) observed in 2014 by GAMIT software. The comparison result of ZTD (zenith total delay) calculated by GPS data and IGS (International GNSS (Global Navigation Satellite System) Service) ZTD product shows that the tropospheric delay based on calculation of CMONOC project data is accurate and reliable. Meanwhile, the PWV (precipitable water vapor) correlation coefficients between GPS observation and upper air sounding is close to 1, which proves that GPS observation data generated in CMONOC project applied to the weather forecast research is feasible. In addition, we make an isoline image for PWV distribution per hour on all stations covered the whole Chinese land area using interpolation algorithms. We observe obvious feature that the precipitable water in north and western area is less than south and east area all over this year. High latitudes area may be dry and low latitudes area is wet.
\end{abstract}

Key word: GPS, CMONOC, precipitable water vapor, troposphere, ZTD.

\section{Introduction}

With the development of GNSS technology, more and more stations are set up. Especially, an important project named CMONOC (Crustal Movement Observation Network of China) have being built, which is made of 260 GNSS (Global Navigation Satellite System) continuous observation reference stations as a main part all over Chinese main land area in order to monitor crustal movement and deformation, service to earthquake forecast [1]. In each station, besides GNSS receiver, there is a meteorological instrument recording temperature, humidity and pressure, and saving to M-file. CMONOC project takes great effect on geoscientific research, atmosphere vapor and so on. It has the feature of high precision, high stability and widespread. Recent years, some researchers get good research achievement on weather forecast study by PWV (precipitable water vapor) calculating with GPS (global position system) data

Corresponding author: Hongbo Shi, master, research field: geodesy. E-mail: hongboshi@foxmail.com.
$[2,3]$. However, some scholars mainly derivated and demonstrated GPS meteorology in theory or tended to measured data validation in small region. It is difficult to model water vapor distribution with ground meteorology parameters accurately because the baseline is short between each station in small area. Elevating angle of one satellite for each station is approximate, it makes high correlation and much uncertainty of zenith delay for small area. Therefore, in order to estimate ZTD (zenith total delay) approach in real environment, the general method is to calculate long baseline data or reduce satellite cut-off attitude angle so that more water vapor in signal oblique path can be obtained. Mapping function used in processing is cosine of cut-off attitude angle [4], coming from carrier phase or pseudorange to zenith delay partial derivative. Thus, PWV inversion with regional GPS observation data is an issue. Essentially, PWV inversion in all over Chinese main land area is an important application and significant to weather forecast research with GPS data of CMONOC project. 


\section{Inversion Theory and Method}

\subsection{Inversion Theory}

As we all know, the GPS signal between satellites and receiver is mainly affected by the troposphere and ionosphere. The path of signal transmission is refracted. There is a time difference of arrival compared with line transmission; we called troposphere or ionosphere delay. For two short distance receivers with double frequency, receiving signal from the same satellite, difference of observation data can eliminate much ionosphere error. But, we have to reduce influence of troposphere delay to station position making use of a closest model. We always see troposphere delay as an unknown number to estimate in data processing, and get station's ZTD of troposphere. ZTD makes up of ZHD (hydrostatic dry delay) and ZWD (wet delay) [8].

$$
Z T D=Z H D+Z W D
$$

Property of the dry atmosphere suits to ideal gas equation and the hydrostatic equation, so we obtain dry Zenith delay's relationship with ground meteorological data [9]:

$$
Z H D=0.0022768 P / f\left(\varphi, h_{0}\right)
$$

where, $P$ is ground pressure of station, $f\left(\varphi, h_{0}\right)$ is $f\left(\varphi, h_{0}\right)=1-0.00266 \cos 2 \varphi-0.00028 h_{0}$, where $h_{0}$ is altitude of station with unit $\mathrm{km}[4,5]$.

Zenith wet delay is the difference zenith total delay of troposphere and dry delay.

Precipitable water vapor is defined as the water column height equaling all of the water vapor in unit area condenses into liquid water above the station. Through separating out zenith wet delay formulas by integral atmospheric refractive index and definitions of precipitable water in meteorology, we can obtain the relationship between ZWD and PWV [8]:

$$
P W V=\prod \cdot Z W D
$$

In the formula, $\Pi=10^{6} /\left[\rho R_{w}\left(K_{3} / T_{m}+K_{2}\right)\right], \rho$ is the density of liquid water $\left(1 \times 103 \mathrm{~kg} / \mathrm{m}^{3}\right) ; K_{2}$ and $K_{3}$ are atmospheric refraction rate constants (the value is $\left.64.79 \mathrm{~K} / \mathrm{hPa}, 3.776 \times 105 \mathrm{~K}_{2} / \mathrm{hPa}\right), R_{W}$ is the ratio of universal gas constant $\left(8.314 \mathrm{~J} \cdot \mathrm{mol}^{-1} \cdot \mathrm{K}^{-1}\right)$ and water vapor molar mass $(18.0152 \mathrm{~g} / \mathrm{mol}), T_{m}$ is calculated by ground observed temperature data and defined as [8]:

$$
T_{m}=\int_{h_{0}}^{\infty} \frac{e}{T} d h / \int_{h_{0}}^{\infty} \frac{e}{T^{2}} d h
$$

where, $e$ is water vapor pressure, and $T$ is ground observed temperature of atmosphere.

\subsection{Resolution Method of High Precision GAMIT Software}

GAMIT is a precision processing software developed by MIT (Massachusetts Institute of Technology), and is one of international high precision softwares. It gives many solutions to improve GPS processing precision, such as eliminating error by difference between two observed quantity, modelling error exactly, and opening source code to make solution flexible. Therefore, GAMIT is applied widely by more researchers on satellite orbit, coordinate of stations, clock error, delay atmosphere, ambiguity of whole cycle and so on. Firstly, we can obtain the millimeter accuracy of total volume including hydrostatic dry delay and wet delay by GAMIT, then solve the hydrostatic dry delay for special model. Lastly, we can obtain the hydrostatic wet delay. By direct ratio relationship between wet delay and water vapor, we can get the millimeter accuracy PWV from zenith. Fig. 1 shows the solution of troposphere delay by GAMIT.

\subsection{Processing Strategy}

Processing strategy is important for getting correct result, including global mapping functions and so on [5]. Table 1 gives main process control factor. 


\begin{tabular}{|l|l|l|}
\hline Raw Observation & Processing Strategy \\
\hline Site information & \\
Receiver/antenna & \\
\hline \hline Aprenna Offset & & Positions \\
Coordinates & & Orbits \\
Orbits [Clocks]/EOP & & EOP \\
\hline Aux. Data & & Tropospheric \\
Ant phase center model \\
Lunar/Solar/Nutation/Tides \\
Leap seconds
\end{tabular}

Fig. 1 The input and output from GAMIT software processing.

Table 1 GAMIT software process parameters setting of control file.

Choice of experiment $=$ RELAX.

Type of analysis $=1$-ITER

AUTCLN redo $=\mathrm{Y}$

Choice of observable $=$ LC_AUTCLN

Zenith delay estimation $=\mathrm{Y}$

Interval zen $=1$

Zenith constraints $=0.05$

Zenith variation $=0.02100$.

Elevation cutoff $=15$

Atmospheric gradients $=\mathrm{Y}$

$\mathrm{DMap}=\mathrm{VMF} 1 \quad \mathrm{WMap}=\mathrm{VMF} 1$

Use map.grid $=\mathrm{Y} \quad$ Use otl.grid $=\mathrm{Y}$

Zenith model $=$ PWL

Light press model: Berne

Model for solving the dry zenith delay: Saastamoinen model (Saastamoinen, 1973).

Mapping function: Vienna mapping function (VMF1) make use of analytical result of digital meteorology [6, 7]. VMF1 is a global digital model. 


\section{Comparison and Analysis of Result}

\subsection{Date Set}

In this study, we have processed the data of about 220 GNSS stations of CMONOC in 2014, including GPS observation data, meteorology data, and IGS (International GNSS Service) precise satellite orbit files, using GAMIT/BLOGK software with a double-difference approach to generate daily solutions. During the data processing of daily solutions, we divide the whole network of CMONOC campaign-mode stations into 5 subnets. Every subnet includes 50 GPS stations. Fig. 2 shows the distributions of all GPS stations of CMONOC.

\subsection{ZTD from Troposphere}

Zenith tropospheric delay presents obvious annual periodic variations trend. Its value is low in the beginning and the end of the year and high in the middle of the year [10]. We extract the zenith total delay estimates from the solution O-file (oexpta.doy) which includes the time of each tabular point and is easily plotted. In order to reveal characteristics of the different latitude tropospheric zenith total delay of Chinese mainland, here give two instances, Chicheng station (HECC) in Hebei province in mid-latitude region and Shaoguan station (GDSG) in Guangdong province in low-latitude region. Fig. 3 shows ZTD time series of HECC station in 2014. On behalf of north China, troposphere delay amplitude variation strongly changes from April to October and becomes stable during the other months in comparison. Especially, it is different in summer and winter. Thus, the changes have significant seasonal variation in mid-latitude. Fig. 4

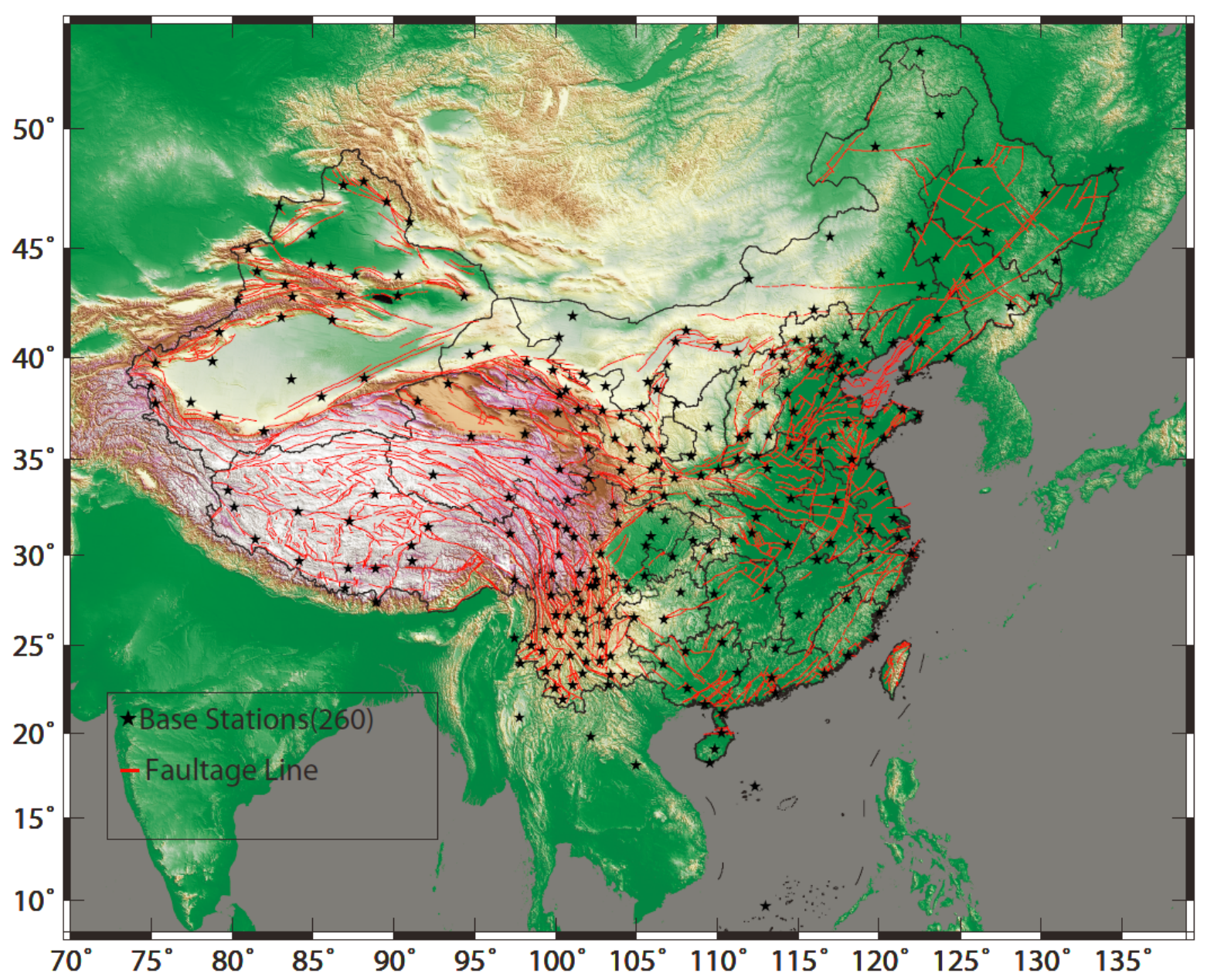

Fig. 2 The distributions of GNSS stations of CMONOC. 
shows ZTD time series of GDSG station in 2014 in low-latitude region. The variation trend is obviously different from HECC station and changes strongly all over the year. The result of these two figures reflects that troposphere variation in south China is more active than in north.

To validate the correctness of ZTD that estimated from CMONOC project data, we compared ZTD result with the products of IGS. CHAN and URUM stations in CMONOC project are almost the same position for IGS so that it is convenient to compare. Figs. 5 and 6 show that the two stations' ZTD all have a good agreement in the trend with IGS. Therefore, we think the tropospheric delay based on calculation of CMONOC project data is accurate and reliable.

\subsection{Comparison with Collocated Meteorological} Sounding Data

In order to test the reliability of PWV result, here we compare the CMONOC GPS-derived PWV data to collocated meteorological sounding observation which is another independent technique to obtain PWV [11]. The upper air sounding data can be downloaded for free from Department of Atmospheric Science at

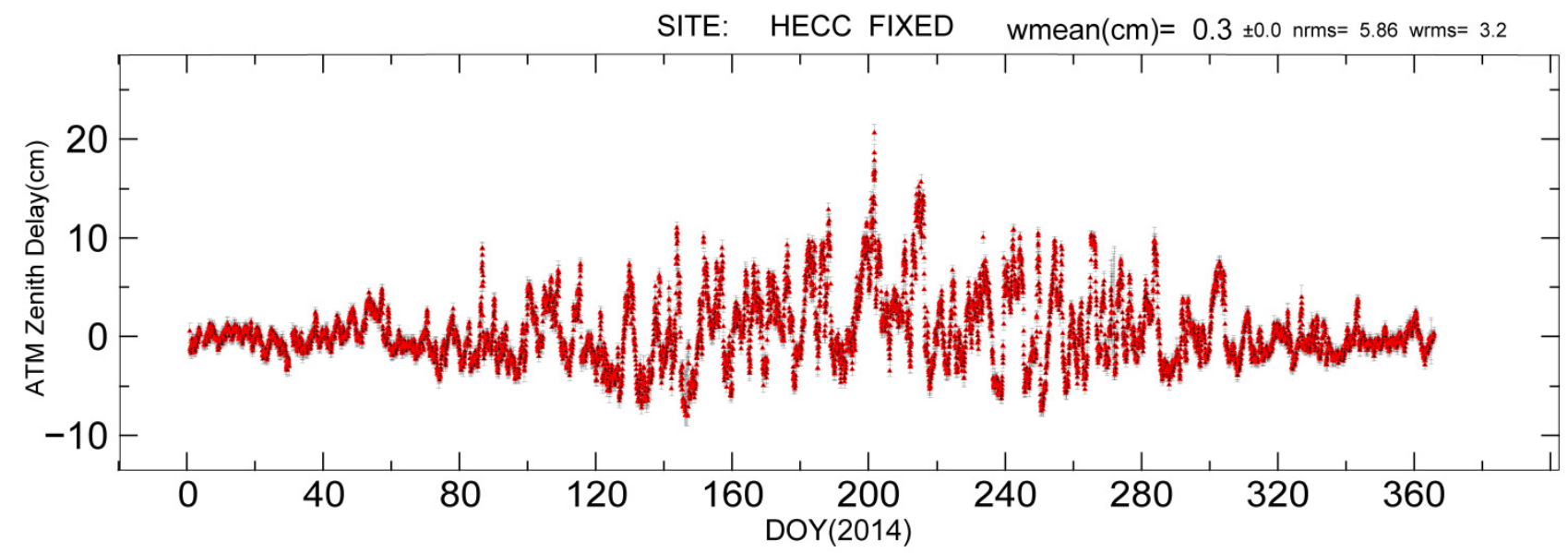

Fig. 3 ZTD time series of HECC station.

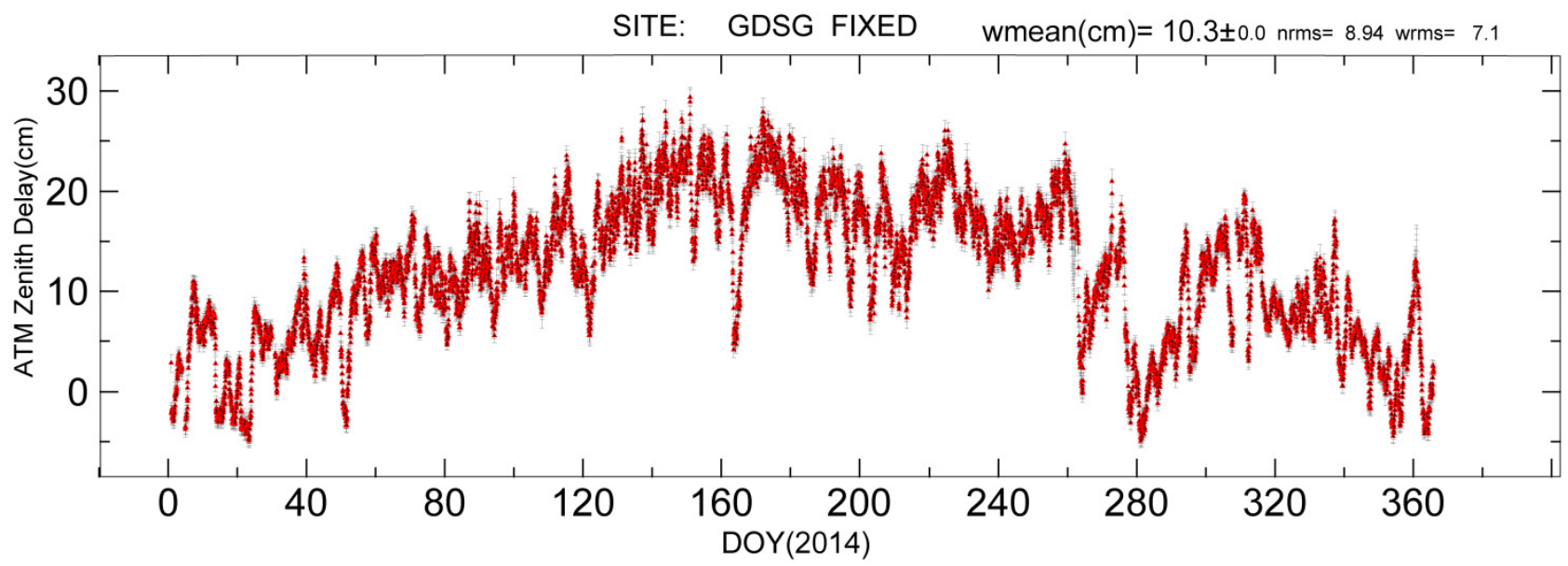

Fig. 4 ZTD time series of GDSG station. 


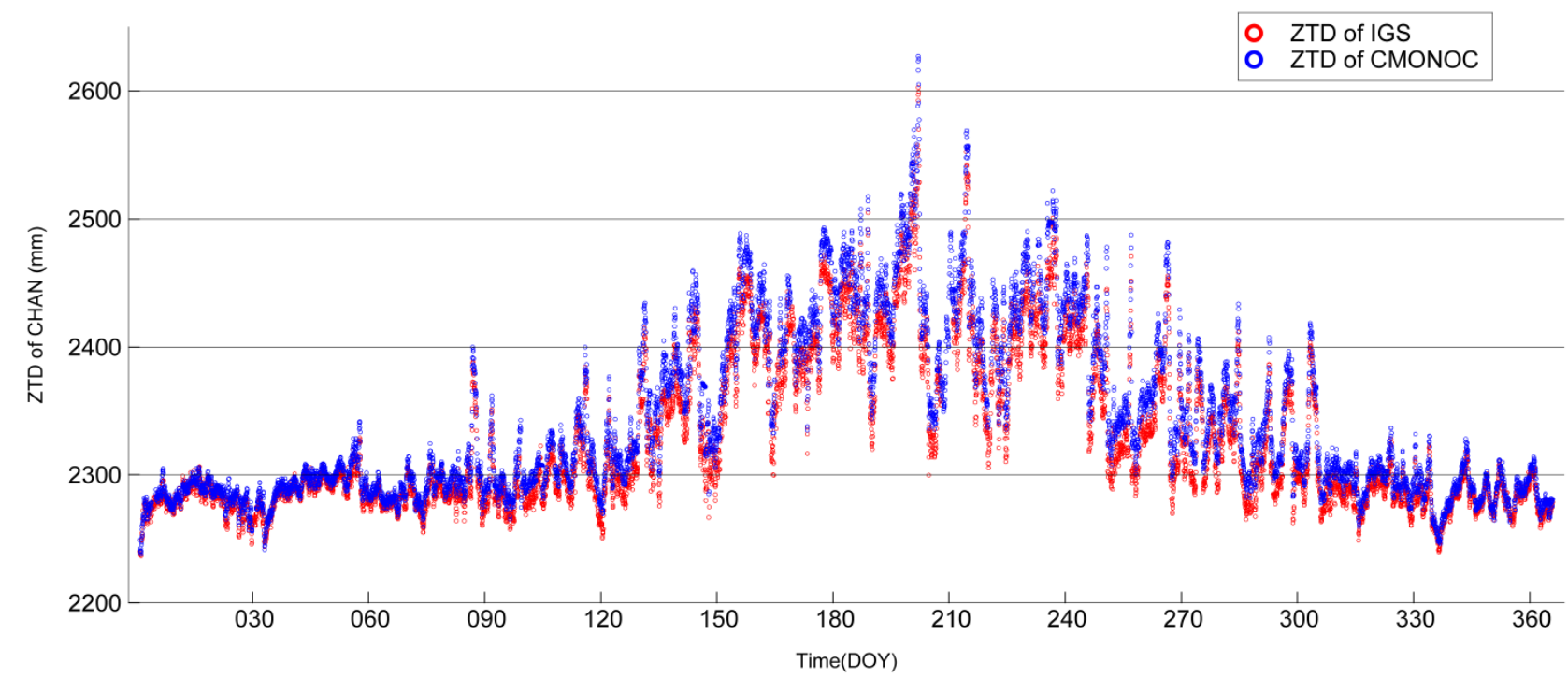

Fig. 5 The ZTD comparison of CHAN station (The red dots represent the ZTD result of IGS and the blue dots represent the ZTD result of CMONOC).

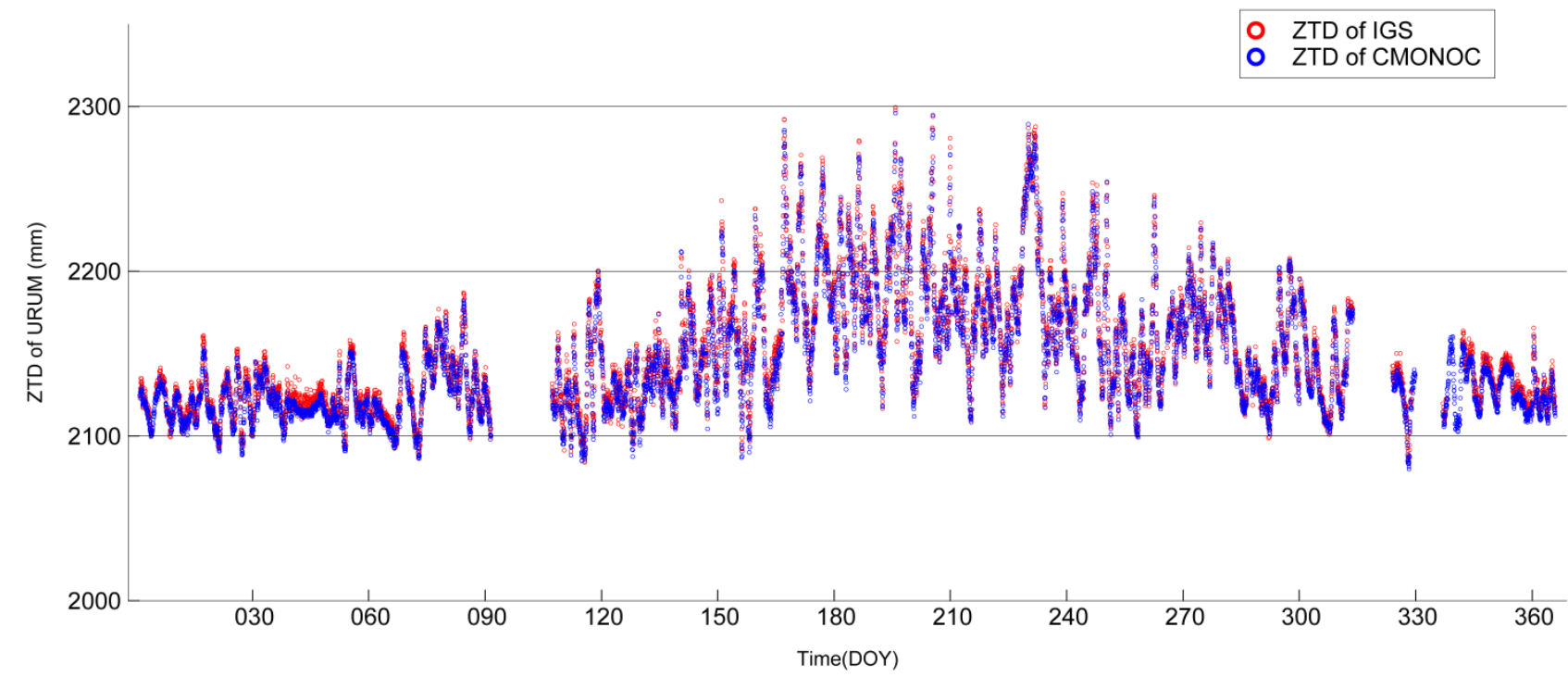

Fig. 6 The ZTD comparison of URUM station (The red dots represent the ZTD result of IGS and the blue dots represent the ZTD result of CMONOC).

Wyoming university. ${ }^{1}$ The solution of upper air sounding data is calculated twice everyday at 0 clock and 12 clock of UTC (Coordinated Universal Time) time. We select a few GPS observation stations of CMONOC collocated with the upper air sounding and compare the PWV result of those two techniques (Fig. 7). The stations' name are HIHK, HLAR, HRBN, NXYC, QHDL, and SXTY. X axis represents the GPS inversion of the pricipitable water vapor extracted from

\footnotetext{
${ }^{1} \mathrm{http} / / /$ weather.uwyo.edu/upperair/sounding.html.
}

inversion result files with 12 hours resolution which starts at 0 clock on January 1, 2014 and ends at 12 clock on December 31, 2014, and has a total of about 720 PWV data point. The $\mathrm{Y}$ axis value is the upper air sounding PWV result and the resolution is consistent with the $\mathrm{X}$ axis. All of value unit is $\mathrm{mm}$. In the figures, black dots represent the value of PWV from $\mathrm{X}$ and $\mathrm{Y}$ axis. The red line is linear fitting line of PWV. The six fitting line's slopes of collocated stations are almost close to 1. They are 1.00077 (a), 1.05302 (b), 0.99977 
(c), 0.98349 (d), 0.96397 (e), 0.99166 (f), respectively. The comparison result indicates the GPS-derived PWV agrees well with the collocated upper air sounding observation. Moreover, adjusted R-squares in these figures are approximate 1 , so the PWV data and corresponding fitting line have good correlation.

\subsection{Distribution Feature of PWV all over China}

We have processed GPS observation data including meteorological files from all the 260 stations, excluding bad data from the stations having problem with meteorological sensors according to interpolation of PWV result about 220 stations. We can get the distribution of PWV all over China.

Distribution of PWV is different in different seasons. According to extracted PWV value, we can make the distribution of inversion PWV all stations per day even per hour. In order to discover the feature of distribution, the precipitable water vapor of stations are grouped by time order. One year is divided into four seasons and every three months are grouped together. The first season includes the time from January to March, the second season from April to June, the third season from July to September and the last season from October to December. We calculate the average PWV value of every station in each group. First season (1-3 months) average precipitable water vapor is $8.16 \mathrm{~mm}$ (Fig. 8a), second season (4-6 months) is $22.58 \mathrm{~mm}$ (Fig. 8b), third season (7-9 months) is $30.66 \mathrm{~mm}$ (Fig. 8c) and the last season (10-12 months) is $11.91 \mathrm{~mm}$ (Fig. 8d).

Fig. 7 shows that the precipitable water in north and western area is less than south and east area all over this year. High latitudes area may be dry and low latitudes area is wet.

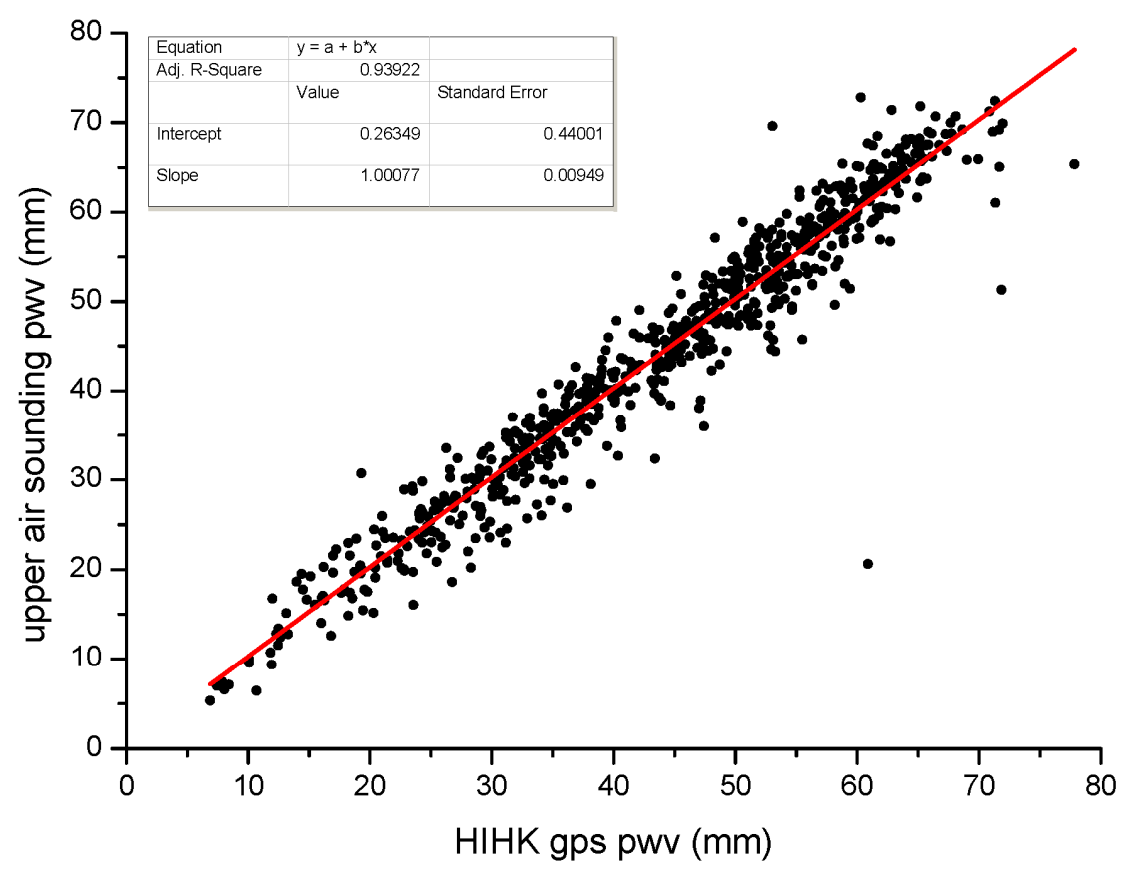

(a) 


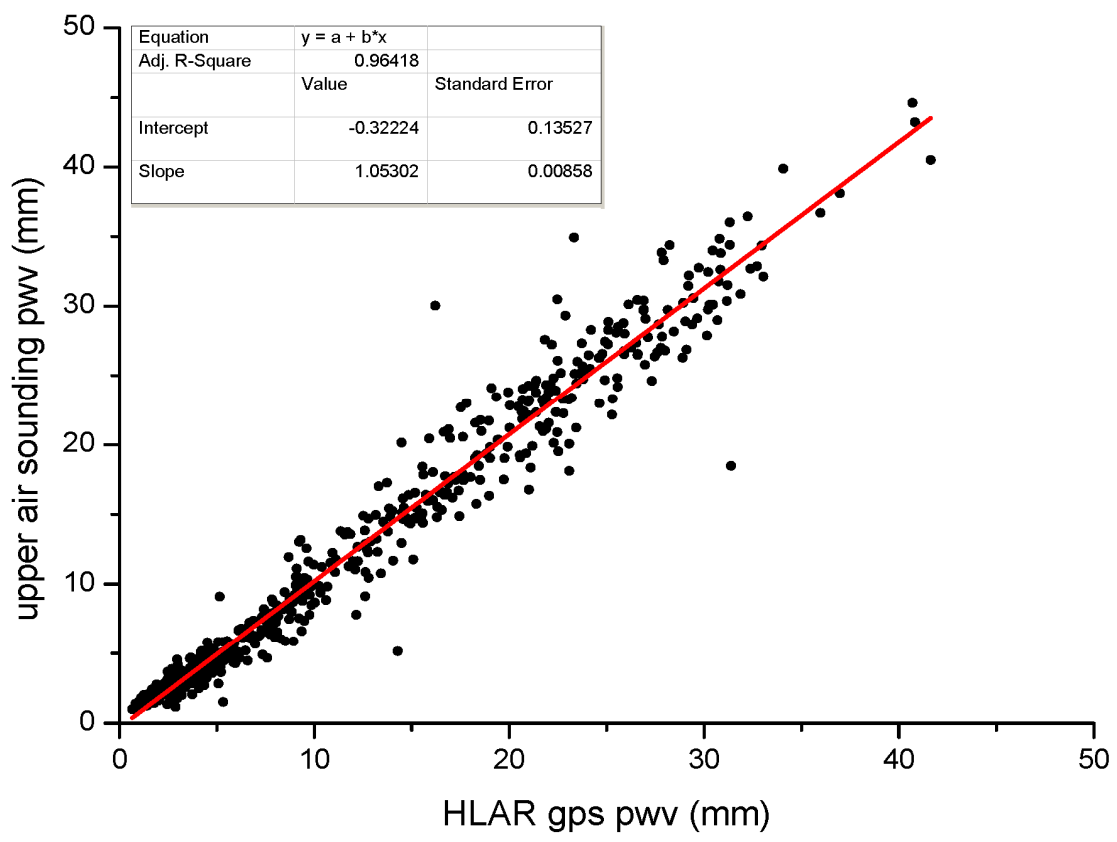

(b)

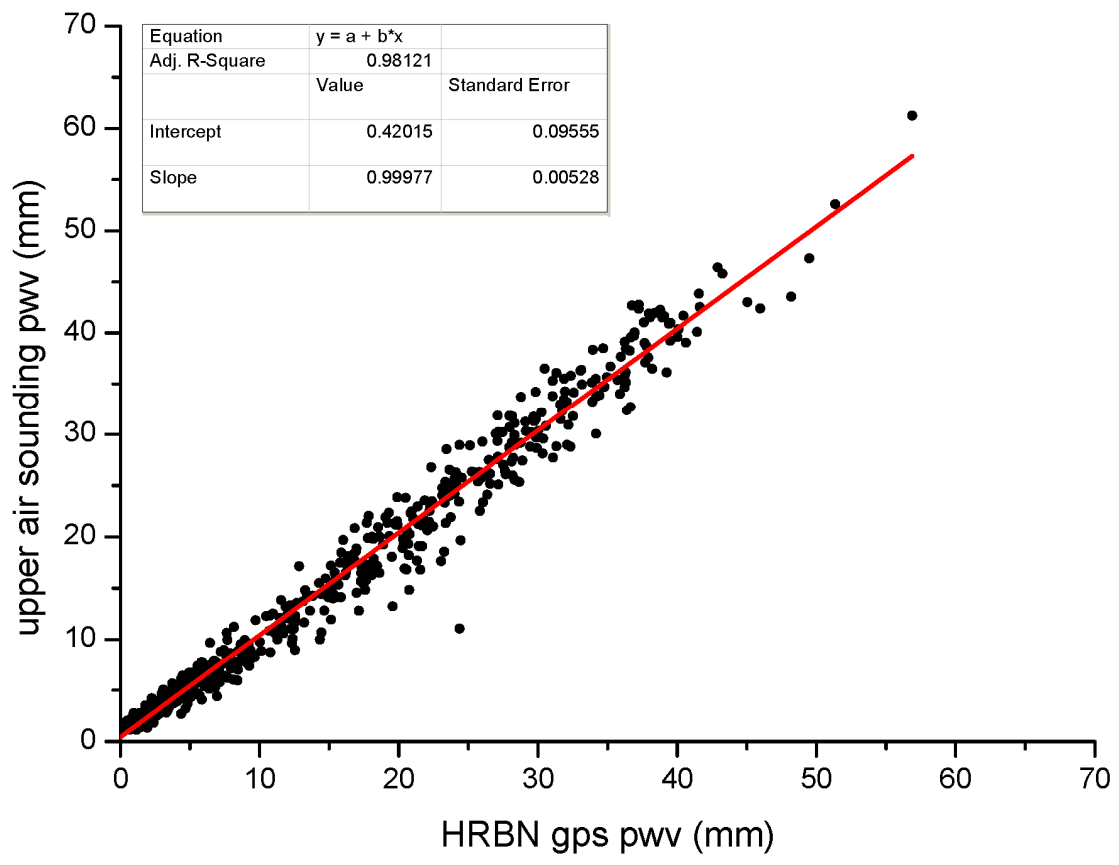

(c) 


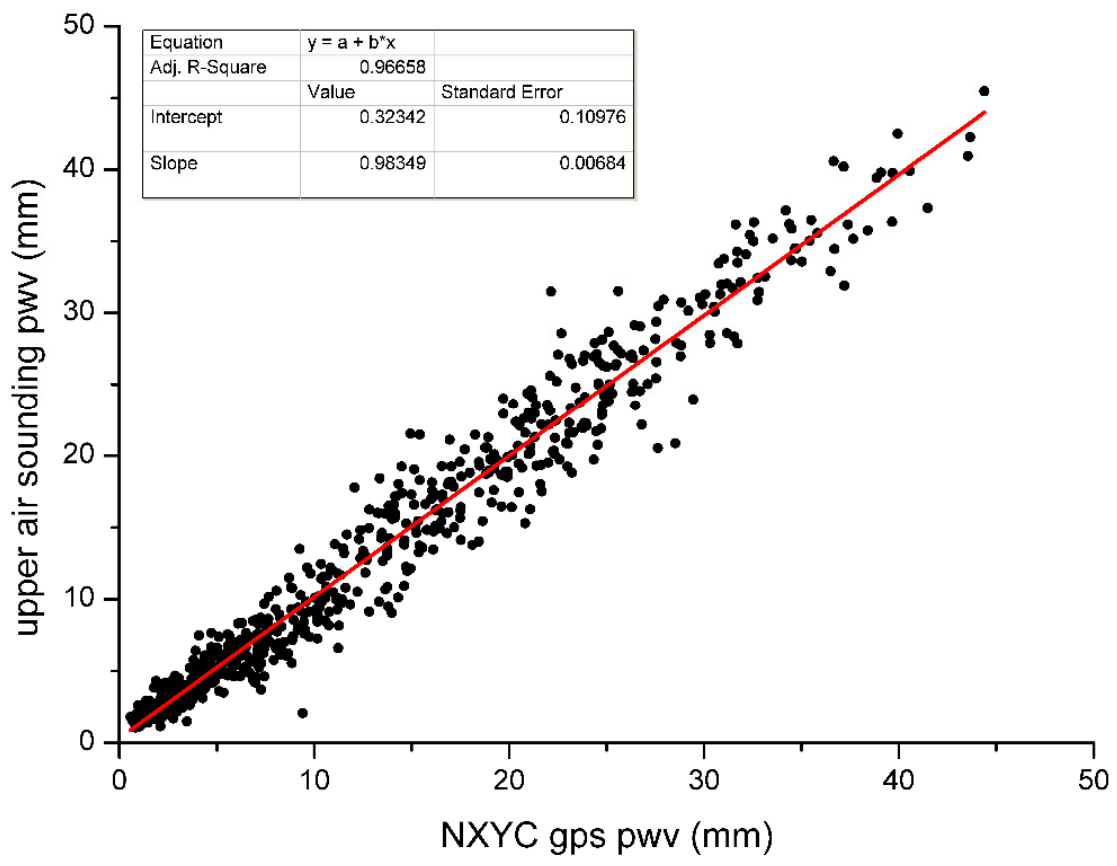

(d)

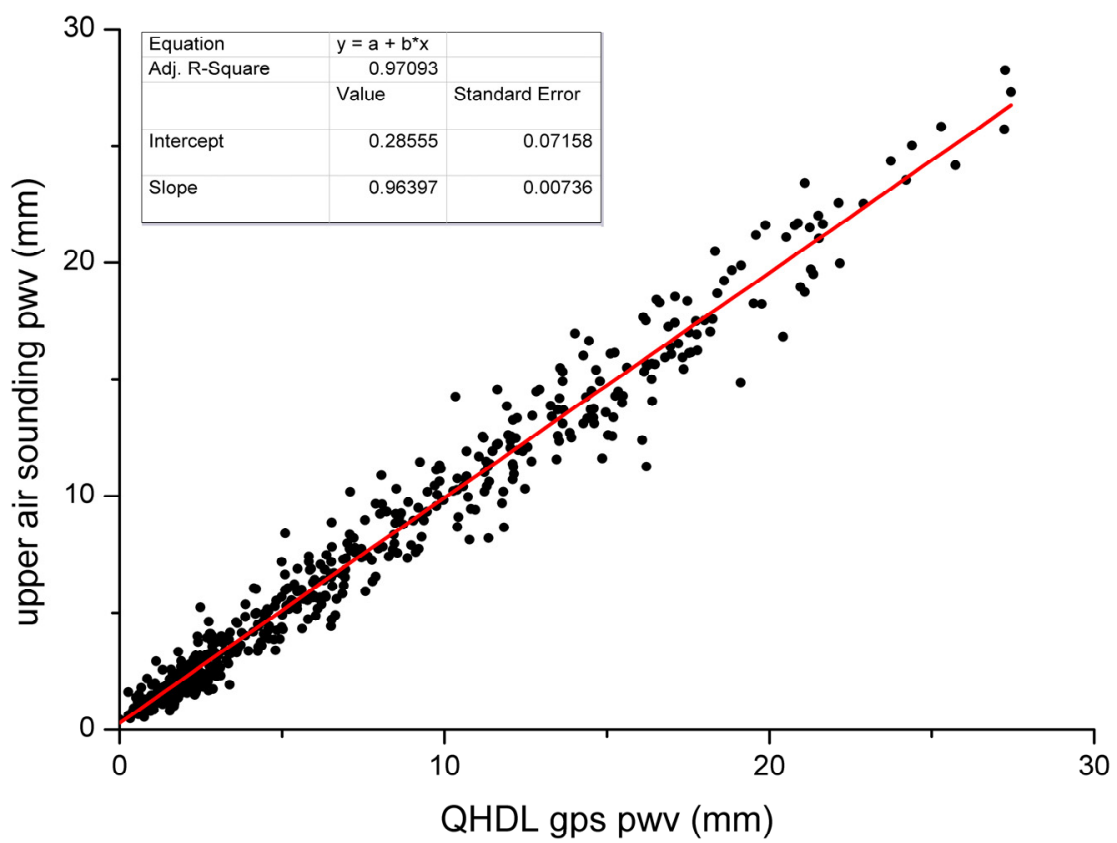

(e) 


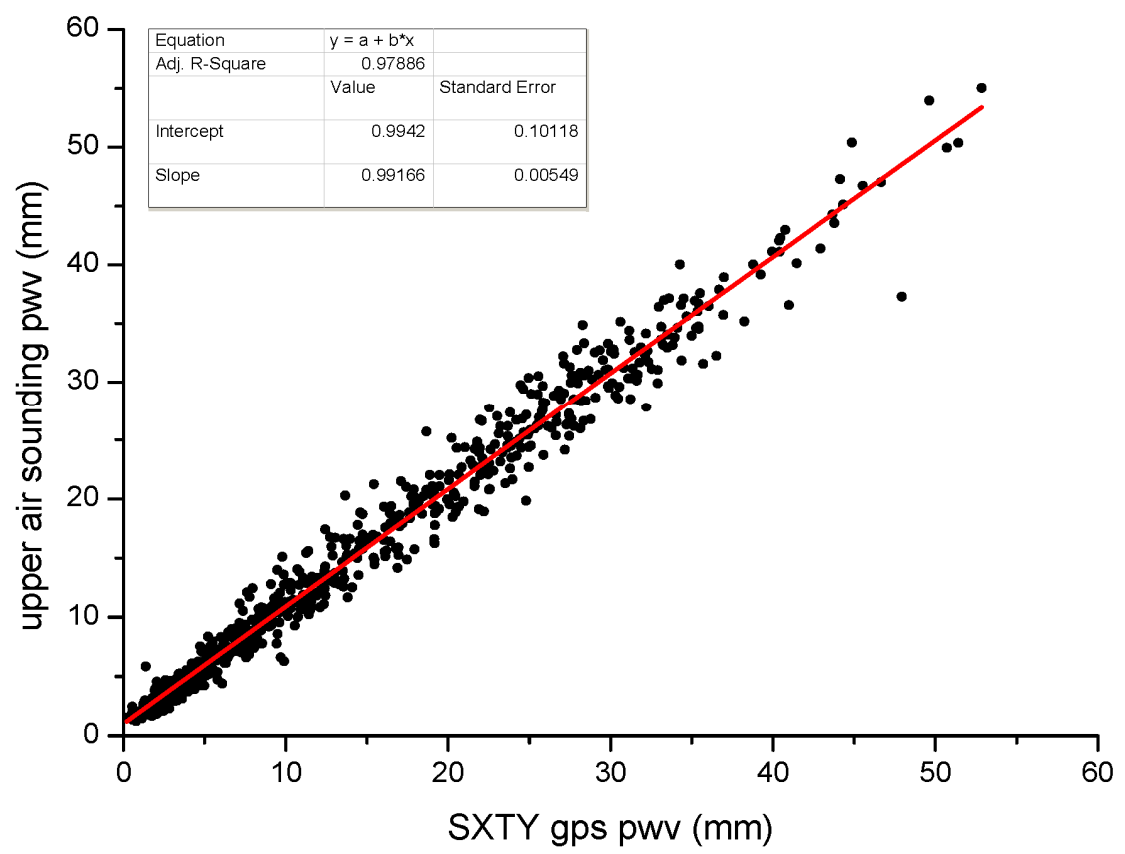

(f)

Fig. 7 Comparison of GPS inversion PWV with upper air sounding at collocated stations: (a) HIHK; (b) HLAR; (c) HRBN; (d) NXYC; (e) QHDL; (f) SXTY.

\section{CMONOC2014_1_90PWV}

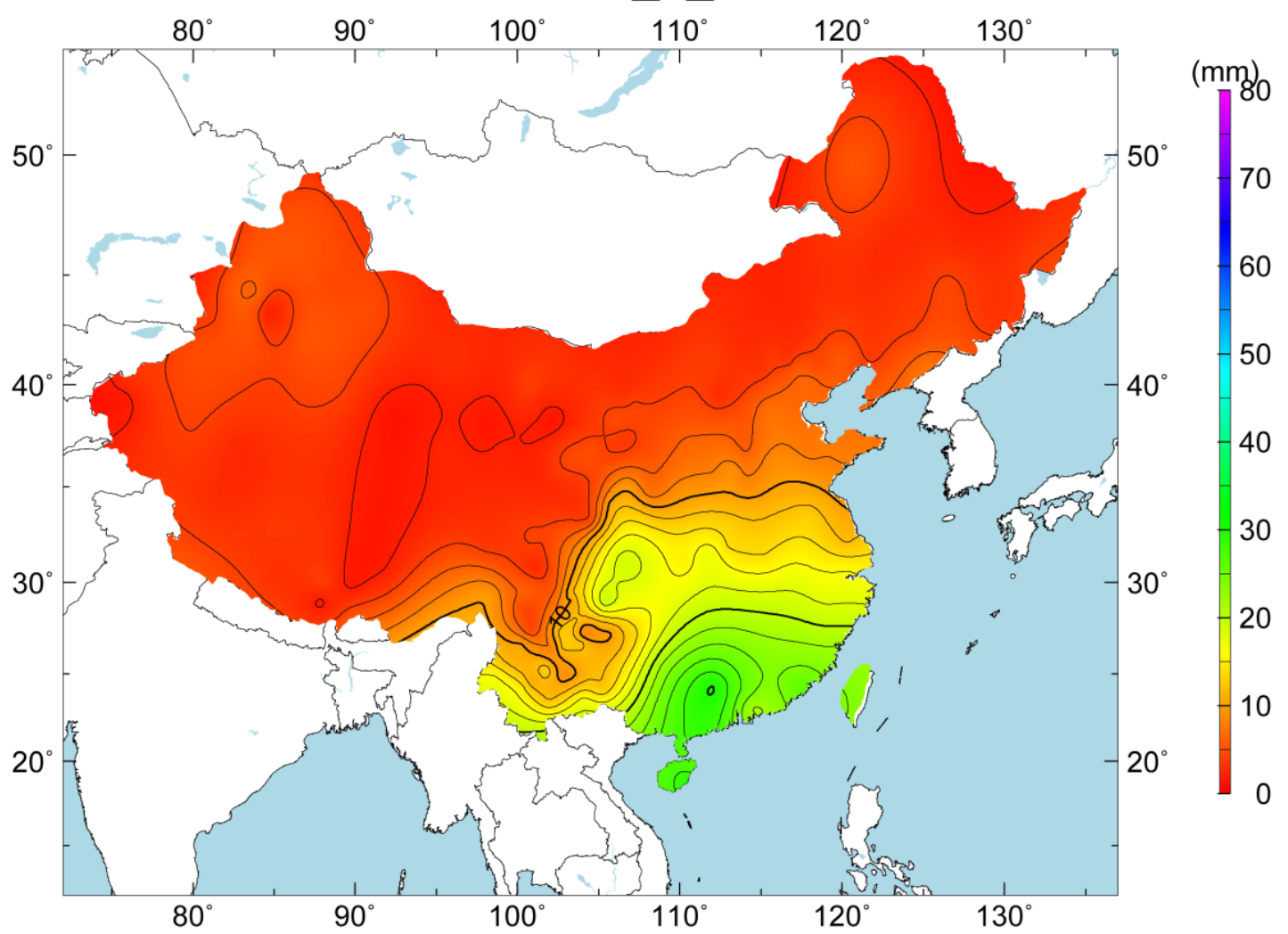

(a) 
CMONOC2014_91_180PWV

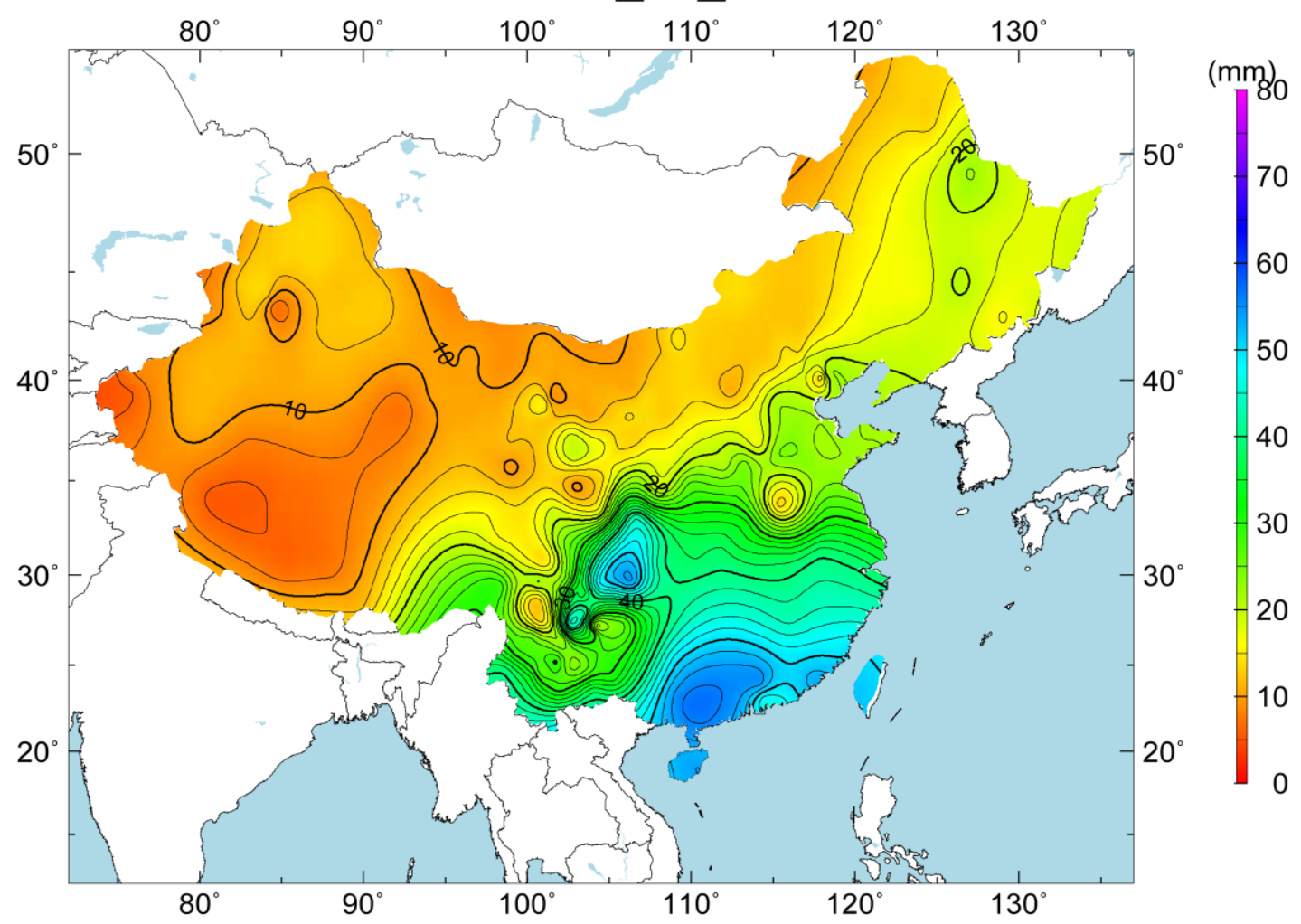

(b)

CMONOC2014_181_270PWV

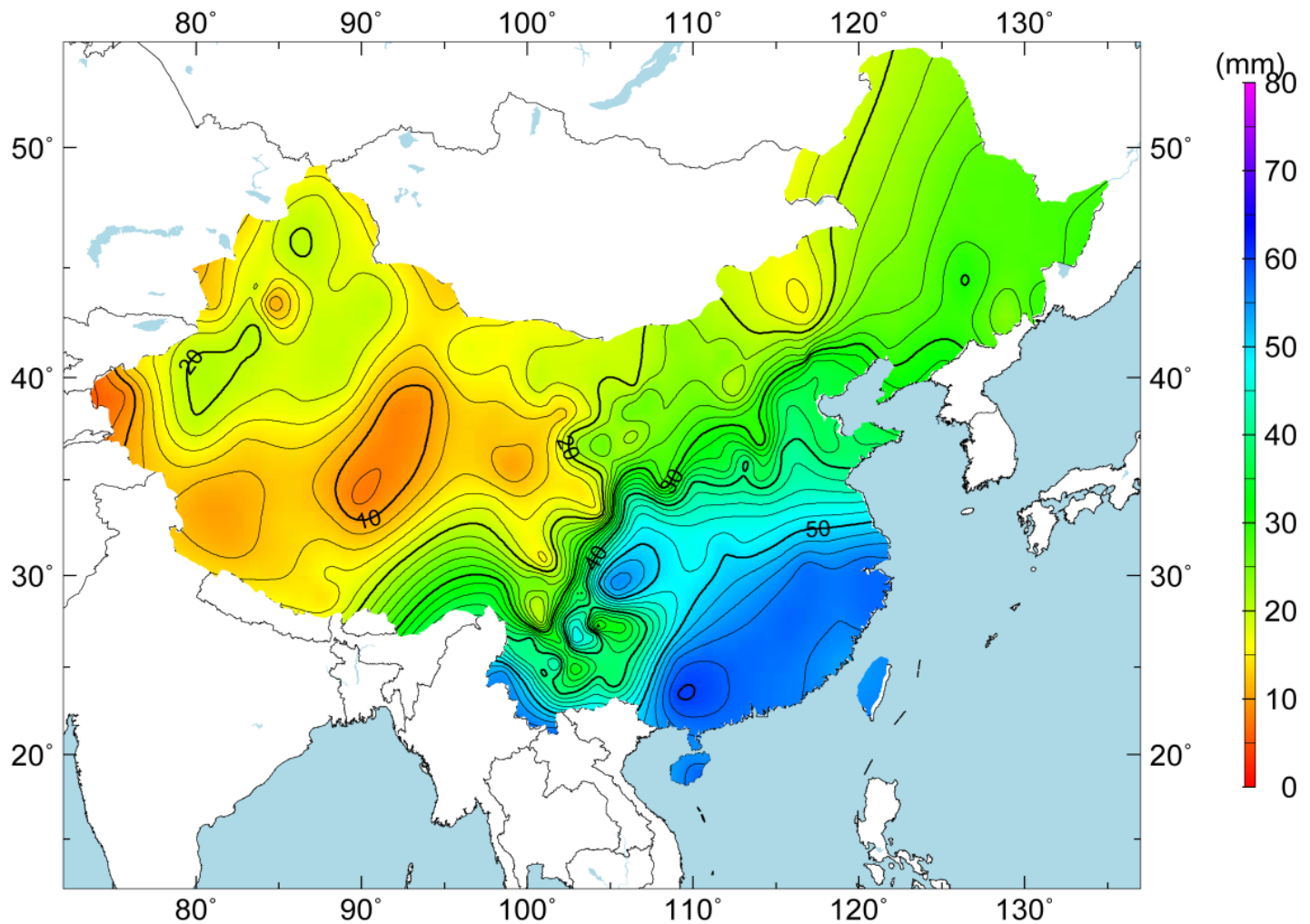

(c) 


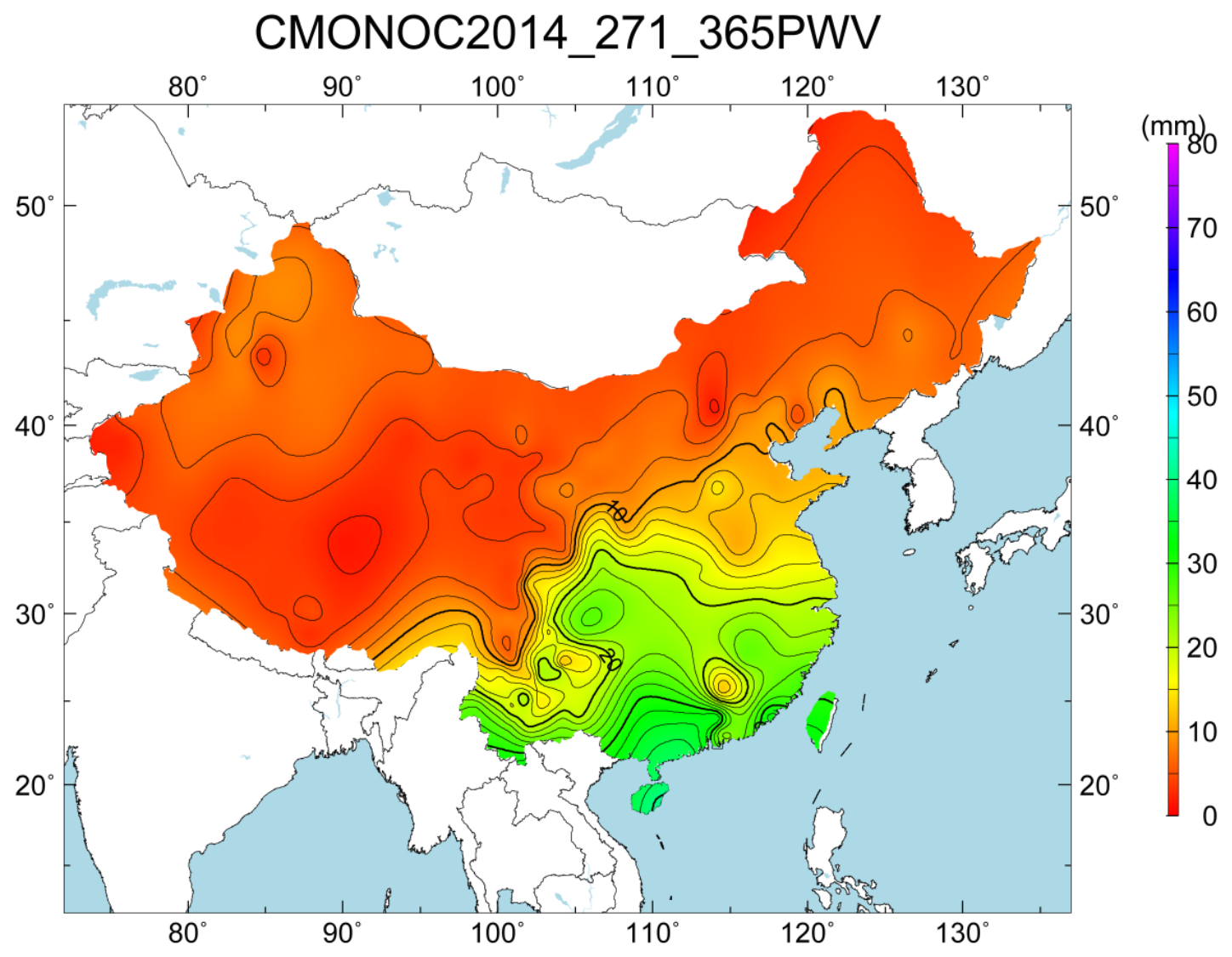

(d)

Fig. 8 Different distribution of PWV all over China in four seasons.

\section{Conclusion}

As a national high precision and reliable GNSS network, CMONOC can supply high quality and continuous observation data to inversion precipitable water vapor. It is one of the best base infrastructure for weather forecast research in mainland of China.

Zenith tropospheric delay variation trend is consistent with IGS ZTD products. At the beginning and the end of the year, zenith tropospheric delay is in low values and in high values at the middle of the year.

The 365 days PWV time series with 1 hour resolution from CMONOC observation data and meteorological files in 2014 indicate that accuracy of PWV by GPS is almost the same as the upper air sounding monitor. Meanwhile, distribution of PWV all over China per hour is able to provide almost real-time rainfall forecast and gives correction or reference for the final weather forecasting.
Depending on more output material, it is possible that we can build tropospheric delay error correction model more suitable for the mainland of China in next research work.

\section{References}

[1] Gan, W., Li, Q., Zhang, R., and Shi, H. 2012. "Construction and Application of Tectonic and Environmental Observation Network of Mainland China." Journal of Engineering Studies 4 (4): 324-31.

[2] Cao, Y., Fang, Z., and Xia, Q. 2005. "Relationship between GPS Precipitable Water Vapor and Precipitation." Journal of Applied Meteological Science 16: 54-9.

[3] Hao, L., Zhao, L., Zhu, M., Bai, X., and Ma C. 2015. "Change Features of GPS/MET Precipitable Water Vapor in Different Precipitation in Lianyungang." Meteorological and Environmental Research 6 (7): 1-4, 9.

[4] Bar-Sever, Y. E., Kroger, P. M., and Borjesson, J. A. 1998. "Estimating Horizontal Gradients of Tropospheric Path Delay with a Single GPS Receiver." Journal of Geophysical Research 103 (B3): 5019-35.

[5] Huang, T., Huang, Z., Zhu, J., Liang, H., Zhang, J.-G. 
2014. "Characteristics of Precipitable Water Vapor Based on Ground-Based GPS in Dalian.” Journal of Meteorology and Environment 30 (2): 45-50.

[6] Yao, Y., He, C., Zhang, B., and Xu, C. 2013. "A New Global Zenith Tropospheric Delay Model GZTD." Chinese Journal of Geophysics 56 (7): 2218-27.

[7] Wang, X., Zhu, W., Yan, H., Cheng, Z., and Chen, J. 1998. "The Preliminary Results of Ground GPS Observation Detection Precipitable Water Vapor." Chinese Journal of Atmospheric Sciences 23 (5): 605-12.

[8] Niell, A. 1996. "Global Mapping Functions for the Atmosphere Delay at Radio Wavelengths." J. Geophys.
Res. 101: 3227-46.

[9] Tang, Y., Liu, L., Yao, C. 2013. "Empirical Model for Mean Temperature and Assessment of Precipitable Water Vapor Derived from GPS." Geodesy and Geodynamics 4 (4): 51-6.

[10] Liu, Y., and Wang, Y. 2016. Study on Urban Disaster Monitoring based on GNSS Technology. Beijing: China Architecture \& Building Press, 69-71.

[11] Jin, S., Luo, O. F., and Gleason, S. 2009. "Characterization Of Diurnal Cycles In ZTD From A Decade Of Global GPS Observations." Journal of Geodesy 83 (6): 537-45. 